\title{
Uso, promoción y difusión del derecho de autor de música folclórica
}

\author{
Use, promotion and dissemination of the Copyright of folk music \\ Uso, promoção e divulgação do Direito autoral da música folk na
}

Artículo recibido en octubre 2019

Arbitraje en noviembre 2019

Aceptación en diciembre 2019

Publicación en enero 2020
Jhoselin Serrudo Terrazas jhudilib@gmail.com

https://orcid.org/0000-0001-6368-4903

Universidad Privada “Domingo Savio", Potosi-Bolívia
RESUMEN

\section{ABSTRACT}

\section{RESUMO} música folclórica na Bolívia. Para tanto, utilizou-se uma metodologia descritiva, com delineamento documental de campo, por sua vez utilizou-se uma abordagem qualitativa e qualitativa, utilizandose os métodos histórico-lógico e de análise-síntese. Por outro lado, a técnica e os instrumentos utilizados, foram o estudo documental, o inquérito e a consulta de especialistas. Além disso, a investigação teve uma população de 200 pessoas relacionadas a direitos autorais. Por sua vez, toda a população foi assumida como amostra. Obteve-se como resultado que o folclore boliviano exige uma política de segurança que emerge do Estado. E concluiu-se que não existe uma proteção adequada dos direitos dos autores e compositores da música folclórica boliviana.

Palavras-chave: Acordo internacional; copyright, direitos conexos; lei 1322; plágio, pirataria 


\section{INTRODUCCIÓN}

El derecho de autor en la actualidad es un tema de estudio que debe ser tratado minuciosamente, la Organización Mundial de Propiedad Intelectual (OMPI, 2014). En la transición de la edad media hacia los tiempos modernos se presentaron en Europa nuevas invenciones y el perfeccionamiento de los medios de comunicación. Es así como apareció la imprenta inventada por Gutenberg en el siglo XV, que hizo posible alcanzar un mayor número de personas sin que estuvieran reunidas en un mismo lugar, lo que formó un mercado que fue desde un principio muy susceptible a las imitaciones y a las falsificaciones. No tardaron en aparecer las reimpresiones una vez salieron los primeros productos de la imprenta, generando el rechazo de los autores y de los impresores, así como de las autoridades. Por ello el origen del derecho de autor se sitúa en la lucha contra la piratería, por motivos materiales, dado el perjuicio económico que ocasionaba, pero también en lo que concierne a los escritos religiosos existía la preocupación de evitar alteraciones y mutilaciones.

Posteriormente hacia el beneficio de los autores de la obra tendió el desarrollo de la protección en Inglaterra, configurando la exclusividad como un derecho del autor, pues se puso fin al monopolio que había adquirido la compañía de Impresores de Inglaterra en 1557, sobre la publicación de obras en todo el país. En efecto, el Estatuto de la Reina Ana de 1709, promulgado en 1710, abolió el monopolio, al atribuir al autor el derecho único de imprimir o de disponer de los ejemplares de una obra. A partir de allí, la forma en que el editor podía beneficiarse del derecho exclusivo de publicar una obra, era en virtud de una cesión que realizara el autor.

En Francia, por su parte, la Revolución de 1789 abolió los privilegios existentes y los Decretos de 1791 y 1793 reconocieron a los autores los derechos de autorizar o prohibir la representación y la reproducción de sus obras, respectivamente. Se enfatizó en la consideración personal del autor, pues se estimaba que su propiedad era la más sagrada y "personal", y ello posibilitó la elaboración futura, por vía de jurisprudencia, del derecho moral (derechos de divulgación, reivindicación de la paternidad, respeto de la obra, retractación) a partir de 1814.

En una primera etapa a lo largo del siglo diecinueve se concretaron contratos estatales bilaterales sobre el reconocimiento recíproco de la propiedad intelectual, pero tales acuerdos bilaterales no eran suficientemente globales ni seguían un patrón uniforme, el cual era necesario para proteger adecuadamente las obras de los nacionales de cada Estado, así como las inversiones asociadas a su explotación más allá de las fronteras propias. (Jaramillo, 2010).

Esta situación condujo a la materialización de tratados multilaterales como el convenio de Berna para la Protección de las Obras Literarias y Artísticas (1886), y otros.

Con ello quedaba cimentada una plataforma de protección internacional a la que sucedió una gran producción legislativa en todos los Estados durante el siglo veinte, y una gran proliferación 
de tratados multilaterales y de revisión de los existentes, todo lo cual desembocó en la estructura de protección por el derecho de autor tal como la conocemos actualmente.

Para Bolivia fue importante contar con una ley de Derecho de Autor al impulso de diferentes organizaciones vinculadas con los autores y artistas, es así que el año 1992, se promulgó la ley de derecho de autor, principal y más importante instrumento jurídico que recoge en sus artículos la mayor parte de los acuerdos y tratados internacionales ratificados mediante ley nacional más tarde por Bolivia, especialmente aquellos administrados por la Organización Mundial de Propiedad Intelectual, como el Convenio de Berna para autores y compositores y el convenio de Roma para intérpretes y ejecutantes.

Como se conoce posteriormente esta ley fue reglamentada, hecho que dio lugar a la conformación de sociedades de gestión colectiva, siendo las primeras en constituirse en Bolivia Sociedad Boliviana de Autores y Compositores SOBODAICOM; Asociación Boliviana de Artistas Intérpretes y ejecutantes ABAYEN y la Sociedad Boliviana de Productores de Fonogramas ASBOPROFON. (Urquidi, 2004)

En la actualidad en Bolivia, no se respeta el derecho de autor, y los derechos que de él emergen, dan paso al plagio, además, la normativa perteneciente al ámbito del derecho de autor no está actualizada en el país. También, se dificultad el registro de derechos de autor en Bolivia por parte de autores y compositores de música folclórica.

A partir de este conjunto de dificultades se formula la siguiente interrogante ¿Cuál es el estado actual del uso, promoción y difusión del derecho de autor de música folclórica en Bolivia?, siendo el objeto de estudio, la propiedad intelectual, y el campo de acción, el derecho de autor en Bolivia.

En correspondencia con el objeto de estudio y el campo de acción se propone como objetivo general de la investigación, analizar el uso, promoción y difusión del derecho de autor de música folclórica en Bolivia.

De esta manera, se presenta una novedad científica la cual radica en la conceptualización de un informe dirigido a orientar e informar la determinación de las causas de la inseguridad jurídica del titular de Derecho de Autor. Por ende, la investigación contribuirá al beneficio de todas las personas que se encuentren afectados por la aplicación del Derecho de Autor.

La propiedad intelectual se divide esencialmente en dos ramas, a saber: la propiedad industrial que, por decirlo en pocas palabras, se refiere a las invenciones, y el derecho de autor, que se aplica a las obras literarias y artísticas; lo cual es de absoluta importancia en la presente investigación, puesto que el derecho de autor figura como objeto de estudio, a continuación se presentan algunos conceptos relevantes que definen el derecho de autor para el avance teórico de la investigación: 


\section{Derecho del Autor}

Según, Fernández (2011), el derecho de autor son las normas y principios que regulan los derechos morales (reconocimiento de la autoría de la obra y el derecho del autor a negarse a hacer obras derivadas) y derechos patrimoniales (derechos valorables en dinero) que la ley concede a los autores, por haber creado una obra literaria, artística, científica o didáctica.

Además el consejo nacional de la cultura y las artes (2013) plantea que el derecho de autor es la protección jurídica que se otorga a los autores y creadores por el solo hecho de haber creado una obra, cualquiera sea su forma de expresión, ya sea literaria o artística, esté publicada o inédita. Esto significa que todo autor de una obra tiene sobre ella un derecho que puede ser ejercido frente a cualquier persona. Las normas y principios que regulan esta protección abarcan las facetas tanto moral como patrimonial del derecho de autor.

Por lo citado anteriormente, se puede analizar que el derecho de autor abarca toda creación artística del intelecto humano, que llega a ser la elaboración novedosa con cierto atractivo que involucra una apreciación social, lo cual incluye a los libros, las obras musicales, las pinturas, las esculturas, las películas y las obras realizadas por medios tecnológicos como programas informáticos y las bases de datos electrónicos; de dicha creación se produce una relación jurídica entre el autor y su obra que nos remite a la persona creadora y su creación, resaltando así el hecho que se reconoce en la mayor parte de las leyes, en el sentido de que el autor goza de derechos específicos tales son el derecho moral así como también el derecho patrimonial en relación con su obra como el derecho de impedir la reproducción deformada de la misma, prerrogativa que solo a él le pertenece, mientras que existen otros derechos, como el derecho de efectuar copias, esto tomando en cuenta el debido permiso que se requiere del autor para realizar duplicaciones de su obra, del que pueden gozar terceros mismos pueden ser cualquier persona ajena a la creación de la obra, a esto se lo denomina protección jurídica, la cual queda inmersa dentro del derecho de autor, a diferencia de la protección de las invenciones, en la normativa de derecho de autor se protege exclusivamente la forma de expresión de las ideas, y no las ideas propiamente dichas.

\section{Derechos conexos}

Según el autor (Gómez, 2006), señala que los derechos conexos son aquellos que brindan protección a quienes, sin ser autores, contribuyen con creatividad, técnica u organización, en el proceso de poner a disposición del público una obra.

A diferencia del derecho de autor, los derechos conexos se otorgan a los titulares que entran en la categoría de intermediarios en la producción, grabación o difusión de las obras. Su conexión con el derecho de autor se justifica, ya que, las tres categorías de titulares de derechos conexos 
intervienen en el proceso de creación intelectual por cuanto prestan asistencia a los autores en la divulgación de sus obras al público.

En este sentido, son derechos conexos al derecho de autor los que la Ley otorga a los artistas, intérpretes y ejecutantes para permitir o prohibir la difusión de sus producciones y percibir una remuneración por el uso público de las mismas, sin perjuicio de las que corresponden al autor de la obra.

La finalidad de los derechos conexos es proteger los intereses legales de determinadas personas y entidades jurídicas que contribuyen a la puesta a disposición del público de obras o que hayan producido objetos que, aunque no se consideren obras en virtud de los sistemas de derecho de autor de todos los países, contengan suficiente creatividad y dimensión técnica y de disposición para merecer la concesión de un derecho de propiedad que se asimile al derecho de autor.

\section{Convenios Internacionales}

Gallardo (2001), indica, el convenio es un escrito celebrado entre Estados con un grado de formalidad menor al de un tratado. Normalmente, un convenio es acordado en aspectos Económicos y Comerciales entre los Estados. Los convenios pueden estar dados entre dos Estados, denominado un Convenio Bilateral, normalmente celebrado para brindar facilidades en materias Comerciales. Pero también existe otra forma de convenio, celebrado entre más de dos Estados, el cual se denomina Multilateral, en el cual, el acuerdo tiene un carácter más normativo respecto de aspectos contemplados dentro del Derecho Internacional. En un Convenio por lo regular se hace la negociación de temas que afectan de manera general a los miembros de la Comunidad Internacional.

\section{Convenio de Berna (OMPI, 1979)}

El objeto del Convenio de Berna es brindar protección a obras literarias y artísticas; y su finalidad está plasmada en orientar, coordinar, simplificar y unificar los criterios dirigidos a encaminar la aplicación el derecho de autor. Dentro del convenio se encuentran las condiciones mínimas de protección, que se refieren a las obras y los derechos que han de protegerse, y a la duración de la protección. En cuanto a las obras, la protección deberá extenderse a todas las producciones en el campo literario, científico y artístico, cualquiera que sea el modo o forma de expresión.

\section{Convenio de Roma (OMPI, 1961)}

La Convención de Roma sobre la Protección de los Artistas Intérpretes o Ejecutantes, los Productores de fonogramas y los Organismos de Radiodifusión fue aprobado en Roma en el año 1961 por la Organización Mundial de la Propiedad Intelectual (OMPI). Esta Convención complementa el Convenio de Berna para la Protección de las Obras Literarias y Artísticas y el 
Convenio de Paris para la protección de la propiedad intelectual. Con un alcance internacional se estableció la Convención de Roma para la Protección de los Artistas Intérpretes o Ejecutantes, los Productores de Fonogramas y los Organismos de Radiodifusión el 26 de octubre de 1961, bajo la administración de la Organización Mundial de la Propiedad Intelectual (OMPI), como un comité intergubernamental integrado por países contratantes, a diferencia del Convenio de París, que está constituido como una Unión. En la actualidad cuenta con 83 países contratantes.

\section{Convenio que establece la Organización Mundial de la Propiedad Intelectual (Convenio de la OMPI, 1967)}

La OMPI es una organización intergubernamental que en 1974 pasó a ser uno de los organismos especializados del sistema de organizaciones de las Naciones Unidas. La OMPI tiene dos objetivos principales. El primero de ellos, es fomentar la protección de la propiedad intelectual en todo el mundo. El segundo, es asegurar la cooperación administrativa entre las Uniones que entienden en materia de propiedad intelectual y que han sido establecidas en virtud de los tratados administrados por la OMPI. La Sede de la Organización se encuentra en Ginebra (Suiza). La Organización tiene oficinas de enlace en Río de Janeiro (Brasil), Tokio (Japón), Singapur (Singapur) y ante las Naciones Unidas, en Nueva York (Estados Unidos de América).

\section{Legislación Nacional aplicable}

\section{Constitución Política del Estado}

El cual, menciona en el artículo 102 que el Estado como tal está encargado del registro y protección de la propiedad intelectual ya sea individual o colectiva, lo cual abarca a las obras y descubrimientos de los autores que constituyan titulares de derecho, los cuales sean artistas, compositores, interventores y científicos tomando en cuenta la normativa que para su aplicación se encuentre vigente.

Por otro lado se toma en cuenta los tratados y convenios en cuanto a la protección de los titulares de derecho de autor, los cuales se han dado a conocer anteriormente.

\section{Ley 1322 (Ley derecho de autor)}

En ella, se establece que los derechos de los autores son derechos personales, siendo así que los titulares del derecho de autor pueden ejercerlos sin previa formalidad, este conjunto de derechos abarca los patrimoniales y morales 
La ley 1322 ampara los derechos de todos los autores bolivianos, de los extranjeros domiciliados en el País y las obras de extranjeros publicadas por primera vez en el País. Con esta ley, el Estado boliviano, se adhiere a la convención de Berna para la protección de las obras Literarias y Artísticas, se adhiere a la Convención Internacional sobre la Protección de los Artistas, Intérpretes o Ejecutantes, los Productores de Fonogramas y los organismos de Radiodifusión (Roma 1961).

La Ley 1322, funciona en coordinación con su reglamento, el Decreto Supremo No. 23907; la Ley de Protección al Arte y Cultura Nacional por el Estado; ley de Imprenta; Ley de Cine; reglamento de La Ley de Cine; Servicio Nacional de Propiedad Intelectual (SENAPI) y el Ejercicio del Depósito Legal.

\section{MÉTODO}

Se realizó un estudio descriptivo bajo el diseño documental de campo, La primera de ella, porque se elaboró un teórico sobre el derecho de autor en Bolivia. Y la segunda, porque se presentó la necesidad de estudiar IN SITU sobre el estado actual de la variable dependiente explicitada.

Por otro lado, la investigación uso como métodos, el histórico-lógico, con la finalidad de estudiar el problema en su desarrollo histórico, analizando la seguridad jurídica del titular de derecho de autor en el País y en otros países, para lograr la recopilación de datos. Y el análisissíntesis, con el objetivo de sistematizar la información sobre el tema y los diferentes criterios para establecer la necesidad de un informe para expresar las causas de la inseguridad jurídica de los titulares de derecho de autor y las falencias existentes en cuanto a la normativa actual.

Para la recolección de datos se usaron como técnica e instrumentos; el estudio documental, el cual estuvo caracterizado en primer lugar por la exhaustiva revisión de libros de registros, libros de declaraciones, libros de legalización y homologación, memorias, apuntes jurídicos, periódicos y folletos, en el Servicio Nacional de Propiedad Intelectual SENAPI, mediante el cual se obtuvo la cantidad aproximada de autores y compositores existentes en Bolivia, puesto que no todos se encuentran registrado, por otra parte se obtuvo un dato exacto de los titulares de derecho de autor que se encuentran actualmente registrados en Bolivia, además de lograr identificar la normativa bajo la cual se encuentran trabajando en dicha institución y el funcionamiento de la misma. Mismo estudio fue realizado en las Ciudades de Sucre y La Paz.

La encuesta a sujetos de derecho de autor, la misma se llevó a cabo para obtener información en cuanto al conocimiento y grado de interés que presentan los autores y compositores bolivianos respecto al derecho de autor en Bolivia, logrando obtener información real de los problemas actuales en cuanto al tema de investigación, se tomó como base a una población de 200 personas, los mismos son de criterio probabilístico, la encuesta fue realizada en las ciudades de Potosí, La Paz, Cochabamba y Sucre. 
Criterio o consulta a expertos, la cual se realizó, a 50 personas entendidas en la materia en las ciudades de Cochabamba, La paz y Sucre, siendo los mismos peritos en la rama de propiedad intelectual y aún más específicamente en el derecho de autor, esto para obtener criterios más acertados sobre la situación actual del derecho de autor en Bolivia y la necesidad existente del conocimiento y desarrollo de las normativas, además de establecer un parámetro de los problemas actuales en cuanto al registro y declaraciones de Derecho de Autor, tomando en cuenta posibles demandas existentes y la posibilidad de defensa de los titulares de derechos.

Seguidamente, la presente investigación contó con una población de 200 personas relacionadas con derecho de autor A su vez, se asumió como muestra la totalidad de la población.

RESULTADOS

En este apartado haremos referencia a los autores y compositores de música folclórica nacional boliviana, tomando como parámetro investigativo los métodos utilizados para la obtención de información, mediante los cuales se ha lograron determinar de manera estadística la importancia del Derecho de Autor.

\section{Dimensión. Autores y compositores en Bolivia}

Según el Libro de Registro de Derechos de autor, revisado en la fecha 11 de Septiembre de 2015, el cual es de acceso público, se ubica en la biblioteca de la planta de Derecho de Autor del Servicio Nacional de Propiedad, se encontró registrado a la fecha 122 autores y compositores de música folclórica boliviana, este registro estuvo previsto a nivel nacional y cuenta con la información de los 9 departamentos de Bolivia. Además, según datos estadísticos de investigación en campo realizadas por el SENAPI afirmó una aproximación de 1150 autores y compositores de música folclórica nacional en Bolivia, tomando en cuenta aquellas personas que realizan trabajos inéditos e incluso publicación privada.

En este sentido, se muestra la tabla 1, la estadística actual de la cantidad de autores y compositores de música folclórica boliviana, tomando como parámetro la base de datos revisada en SOBODAYCOM, puesto que la revisión documental tiene un alcance más amplio que los documentos revisados en el SENAPI.

Tabla 1. Cantidad de autores y compositores música folclórica de Bolivia.

\begin{tabular}{ccc}
\hline Alternativas & FRECUENCIA & \% \\
\hline Registrados & 154 & $\mathbf{1 5}$ \\
No registrados & 896 & 85 \\
TOTAL & $\mathbf{1 0 5 0}$ & $\mathbf{1 0 0}$ \\
\hline
\end{tabular}


La Tabla 1, muestra que el $85 \%$ de los autores y compositores bolivianos no han realizado la declaración de sus creaciones como propiedad, y mucho menos han realizado el registro de los Derechos de Autor, además de tomar en cuenta de que un porcentaje mínimo que es el 15\% de los autores y compositores de música folclórica boliviana realizan el registro o declaración de su Derecho de Autor.

Así que, se afirma que no existen dificultades para el registro de Derecho de Autor en Bolivia, ya que, son pocos los artistas en el ámbito del folclore nacional que se animan a registrar su Derecho de autoría.

\section{Dimensión. Obras registradas}

Mediante la revisión documental se logró obtener una aproximación de las obras existentes en Bolivia, puesto que no es posible determinar con exactitud y precisión la cantidad de obras musicales folclóricas bolivianas debido a que no todos los autores y compositores registran dichas obras.

En la Tabla 2, se da a entender en datos precisos la cantidad de obras registradas o declaradas en el Servicio Nacional de Propiedad Intelectual así como también en la Sociedad Boliviana de Autores y Compositores.

Tabla 2. Obras musicales folclóricas de Bolivia.

\begin{tabular}{ccc}
\hline Alternativas & FRECUENCIA & $\%$ \\
\hline Registrados & 523 & 11 \\
No registrados & 4277 & 89 \\
TOTAL & $\mathbf{4 8 0 0}$ & $\mathbf{1 0 0}$ \\
\hline
\end{tabular}

En esta caso, se muestra que solo el $11 \%$ de las obras folclóricas musicales existentes en Bolivia están registradas, esto generalmente se refiere a aquellos autores y compositores de música folclórica boliviana reconocida, por otro lado el $89 \%$ de todas las obras no se encuentran registradas ni tampoco se encuentran declaradas como propiedad por un titular. Expertos en la materia aseguran que dichas obras no son registradas debido a que los compositores en un gran porcentaje son del área rural de Bolivia, por lo cual pocos tienen acceso o información en cuanto a los derechos que como autores y compositores de música folclórica boliviana merecen.

\section{Dimensión. Protección legal}

Este punto fue determinado por la entrevista realizada al Director General de la sociedad boliviana de autores y compositores, en donde indicó que el registro de Derecho de autor en el país de Bolivia, no es necesario puesto que la ley así lo establece, sin embargo es necesario para asegurar la protección legal, el registro, de las declaraciones firmadas auténticas de autores y compositores, esto para la protección y garantía de los beneficios patrimoniales y en menor proporción en cuanto a los derechos morales que cada autor y compositor merece. 
Por otro lado se realizó una entrevista a un profesional de la planta jurídico Legal de SOBODAYCOM en Bolivia, quien nos dio a conocer lo siguiente; para la legitima protección del derecho de autor muchas veces se ha visto por necesario el registro o la declaración, aunque la ley así no lo especifique, las diversas pruebas que algún sujeto pueda presentar en caso de defensa de un derecho legítimo en otras ramas, pueden ser objetivas lo cual en caso del derecho de autor no sucede, porque no existe manera lógica objetiva de demostrar la propiedad creativa no tangible, por lo cual muchas veces es necesario realizar el registro, debido a que la declaración firmada que se realiza en SOBODAYCOM, va más a un carácter patrimonial.

\section{Dimensión. Casos de plagio}

En la Tabla 3, se muestra que el $100 \%$ el cual representa el total de la población tienen conocimiento de los casos de plagios en Bolivia. En este sentido, tantos autores como compositores son consciente del plagio que existe en el país, aclaran que no es simplemente uno sino son varios en su trayectoria musical.

Tabla 3. Casos de plagios.

\begin{tabular}{ccc}
\hline Alternativas & FRECUENCIA & $\%$ \\
\hline Si & 200 & 100 \\
No & 0 & 0 \\
TOTAL & $\mathbf{2 0 0}$ & $\mathbf{1 0 0}$ \\
\hline
\end{tabular}

Tabla 4. Personas víctimas de plagio.

\begin{tabular}{ccc}
\hline Alternativas & FRECUENCIA & $\%$ \\
\hline Si & 128 & 64 \\
No & 72 & 36 \\
TOTAL & $\mathbf{2 0 0}$ & $\mathbf{1 0 0}$ \\
\hline
\end{tabular}

\section{Dimensión. Formas de defensa del derecho de autor}

En la Tabla 4 se muestra que el $64 \%$ de la población que respondió a la encuesta si ha sido víctima de plagio y el $36 \%$ señaló que no. En este sentido, la mayoría de la población aseguró que por lo menos una de sus obras ha sido objeto de plagio muchas veces debido a que dichos autores y compositores no son conocidos en el medio artístico, además algunas veces hasta fueron objeto de burla, al proclamar una obra como suya, por otro lado, se encuentra la falta de respeto en cuanto al permiso de uso de algunas obras musicales puestas en escena que en la mayoría son de carácter lucrativo sin dar ninguna remuneración al compositor o autor de la obra; y por otro lado, la minoría indicó que sus obras no han sido plagiadas o que por lo menos no tienen conocimiento de ello. 
En la Tabla 5 se muestra que el $8 \%$ de la población no tiene conocimiento de la normativa actual en vigencia, sin embargo el $92 \%$ aseguran tener pleno conocimiento de la normativa.

Tabla 5. Conocimiento de la normativa vigente sobre derecho del autor.

\begin{tabular}{ccc}
\hline Alternativas & FRECUENCIA & \% \\
\hline Si & 185 & 92 \\
No & 15 & 8 \\
TOTAL & $\mathbf{2 0 0}$ & $\mathbf{1 0 0}$ \\
\hline
\end{tabular}

Por lo tanto, la mayoría de los encuestados indicaron tener el conocimiento de la existencia de la normativa vigente sobre el derecho de autor, pero una minoría indicó que no tienen conocimiento de la normativa actual en vigencia, y en ocasiones ni llegan a conocer la existencia de la misma, esto debido a que son autores y compositores de música folclórica del área rural de Bolivia.

En la Tabla 6 se muestra que el $98 \%$ de los autores y compositores encuestado no sienten que el derecho de autor esté garantizado en Bolivia, mientras que solo un $2 \%$ indicaron que si sienten seguridad al ser garantizado el derecho del autor en el país.

Tabla 6. Seguridad del titular de derecho de autor garantizada.

\begin{tabular}{ccc}
\hline Alternativas & FRECUENCIA & $\%$ \\
\hline Si & 3 & 2 \\
No & 197 & 98 \\
TOTAL & $\mathbf{2 0 0}$ & $\mathbf{1 0 0}$ \\
\hline
\end{tabular}

Por lo tanto, quedó demostrado que la mayoría de los encuestados están de acuerdo en señalar que el Derecho de Autor en Bolivia no está garantizado, puesto que existe un gran descuido en cuanto al respeto que se merece.

El folklore boliviano necesita una política de seguridad que emerja del Estado, un porcentaje del presupuesto para la difusión internacional para dar a conocer al mundo entero las obras musicales creadas por autores y compositores de música folclórica nacional boliviana, puesto que los problemas suscitados en cuanto a la protección del derecho de autor y los medios de defensa del mismo no son suficientes tanto nacional como internacionalmente. 


\section{Propuesta sobre informe del uso, promoción y difusión del derecho de autor de música folclórica en Bolivia}

\section{Análisis circunstanciado de los hechos}

El derecho de autor es un conjunto de normas jurídicas y principios que regulan los derechos morales y patrimoniales que la ley concede a los autores por el solo hecho de la creación de una obra literaria, artística, musical, científica o didáctica, esté publicada o inédita, y que está reconocido en la Declaración Universal de los Derechos Humanos de 1948, como uno de los derechos humanos fundamentales. Sin embargo, 22 años antes de emitida la Declaración Universal de los Derechos Humanos se creó en París (Francia), la Confederación Internacional de Sociedades de Autores y Compositores (CISAC), actualmente convertida en una red mundial líder de sociedades de autores y agrupa a 231 organizaciones de gestión colectiva en 121 países del mundo, con el fin de proteger, promover, posibilitar y facilitar que los autores, compositores y titulares puedan ejercer sus derechos. En Bolivia la encargada de velar por esos derechos es la Sociedad Boliviana de Autores y Compositores de Música (SOBODAYCOM).

Seguidamente, se analiza que Bolivia debe trabajar intensamente en el registro de obras, así como en la valoración y promoción de su rico patrimonio cultural artístico y en el apoyo particular a la SOBODAYCOM, puesto que la riqueza cultural en cuanto al folclore boliviano no está siendo valorado, y es lo que evidentemente pasa con muchos países, que le dan mayor prioridad al talento extranjero, muchas veces debido a los medios de comunicación, que generalmente se encargan de la difusión de moda colectiva, lo cual implica la dejadez en el ámbito cultural nacional, por lo cual se requiere políticas de difusión y promoción en cuanto al folclore nacional dentro de los organismos de difusión interna, para poder lograr expandir la cultura nacional. En ese sentido, es necesario que absolutamente todos los habitantes de Bolivia y, obviamente y sobre todo los principales implicados en la temática, apoyen la identidad y el patrimonio cultural boliviano y se ocupen de registrar la mayor cantidad de obras no sólo a nivel nacional sino a nivel internacional, considerando que el repertorio boliviano es bastante rico y se pueden hacer nuevas versiones de las grandes composiciones pasadas y de esa manera beneficiar o bien a los autores y compositores o bien a sus sucesores, en caso de que el creador haya muerto.

Por otro lado, en términos generales, en lo que hace a las recaudaciones, la Confederación Internacional de Sociedades de Autores y Compositores obtiene el $32 \%$ del total de sus ingresos de los aportes que hacen la radio y televisión por la difusión de música. Le sigue con un $22 \%$ las recaudaciones por concepto de reproducciones discográficas (los discos originales que compran los usuarios). Después, un $12 \%$ de sus ingresos los obtiene de la difusión de música por satélite y audiovisuales y otro $10 \%$ por la música en vivo. 
Por consiguiente, en Bolivia, donde el pago por derechos de autor en todos los ámbitos, es uno de los más precarios de la región, el mayor porcentaje de los escasos 30 mil dólares anuales que recauda la SOBODAYCOM tienen su fuente en los conciertos y las presentaciones en vivo.

\section{Análisis Jurídico relevante}

Dos razones fundamentales pueden aducirse en general para explicar la necesidad de que los países promulguen leyes de protección de la propiedad intelectual y con mayor prioridad para el derecho de autor en cuanto a la cultura nacional. En primer lugar, a fin de amparar en las leyes los derechos morales y patrimoniales de los creadores respecto de sus creaciones y los derechos del público para tener acceso a las mismas. En segundo lugar, con miras a promover la creatividad y a los fines de la difusión y la aplicación de los resultados de la misma, así como para fomentar prácticas comerciales legales que contribuyan a su vez al desarrollo económico social de Bolivia, por ser del carácter folclórico nacional.

\section{Ley $N^{\circ} 1322$ sobre Derechos de Autor del 13 de abril de 1992}

Ésta sostiene que el derecho de autor que se tiene sobre una obra literaria, artística o científica realizada en cualquier forma de expresión y sobre cualquier medio o soporte por un autor nace con la creación misma de la obra sin necesidad de su registro; éste sólo garantizaría su seguridad jurídica. El derecho de autor sólo puede ser sostenido por una persona natural, tal es el caso de los autores y compositores de música folclórica boliviana "sin embargo, el Estado, las entidades de derecho público y las personas morales o jurídicas pueden ejercer los derechos de autor como titulares derivados". El autor, de esta manera, concede parte de sus derechos, mediante prescripciones contractuales que se establezcan bajo su aquiescencia y las disposiciones específicas establecidas para cada sector. La única manera de renunciar a tales derechos, sería entregando la obra, bajo la figura del anonimato, al dominio público sin que pueda ser imputada su paternidad; incluso esta acción la realiza la voluntad del propio creador de la obra.

Incluidos en los derechos de autor, aparecen los derechos conexos: aquellos relativos a los derechos de: primero los intérpretes y ejecutantes de música, segundo los productores de fonogramas y tercero los organismos de radiodifusión; la especificación de estos sectores se realiza ya en la Convención de Roma (1961).

Para la protección legal (patrimonial y moral) de los autores, compositores, artistas, intérpretes o ejecutantes, se reconoce su asociación, no pudiendo constituirse más de una sociedad para cada rama o especialidad literaria o artística de los titulares reconocidos por la Ley, disponiendo, además, que contarán con personería jurídica y patrimonio propios a las finalidades que la misma ley establece. 
Con las amplias limitaciones de que cada autor y/o compositor tenga que custodiar la reproducción y difusión de sus obras musicales que se le permite en los Arts. 17 y 20 del Reglamento de la Ley 1322, delegarían a las sociedades de gestión colectiva esta labor. La normativa claramente sintetiza: Las sociedades podrán ejercer las atribuciones de defender los derechos morales y patrimoniales de sus afiliados y representarlos ante autoridades o terceras personas pudiendo suscribir contratos y documentos, ejercer el mandato de sus afiliados de recaudar y liquidar a favor de ellos, pudiendo además establecer convenios de reciprocidad con sociedades nacionales y/o extranjeras para el adecuado cumplimiento de su objeto social.

En el País sólo se constituyeron legalmente tres de estas sociedades: La Sociedad Boliviana de Autores y Compositores de Música (SOBODAYCOM), la Asociación Boliviana de Artistas Intérpretes y Ejecutantes de Música (ABAIEM) y la Asociación Boliviana de Productores de Fonogramas y Videogramas (ASBOPROFON); las tres, a su vez, constituyeron la Asociación Recaudadora de Derechos de Ejecución Pública ASA sigla que toma la inicial de cada sociedad como institución sin fines de lucro y mecanismo operativo para la gestión de derechos, con facultades para autorizar, recaudar y administrar el repertorio musical nacional y extranjero, los derechos de ejecución pública musical.

\section{Código Penal (Ley №1768, del 10 de marzo de 1997)}

Indica que quien con ánimo de lucro, en perjuicio ajeno, reproduzca, plagie, distribuya, publique en pantalla o en televisión, en todo o en parte, una obra literaria, artística, musical, científica, televisiva o cinematográfica, o su transformación, interpretación, ejecución artística a través de cualquier medio, sin la autorización de los titulares de los derechos de propiedad intelectual o de sus concesionarios o importe, exporte o almacene ejemplares de dichas obras, sin la referida autorización, será sancionado con la pena de reclusión de tres meses a dos años y multa de sesenta días.

Las violaciones a los derechos de autor serían aquellas que atenten contra los derechos morales y patrimoniales del autor y/o compositor, o con los conexos: los derechos de paternidad sobre la obra, de conservación de la integridad de la obra, el de su comunicación y conservación en el anonimato (para los morales); los derechos a la reproducción, transformación y comunicación total o parcial de la obra (para los patrimoniales).

Las violaciones al derecho de autor así entendidas, quedarían restringidas por el Código Penal que sólo sancionaría penalmente la utilización lucrativa o comercial que se haga de la obra, o parte de ella, o aquellas actividades que involucren la comercialización de obras ilícitas; la normativa penal es clara en este aspecto, sin embargo se requiere de un largo proceso, además de la necesidad de evidencia para demandar la titularidad de una obra, peor aún si en el caso de canciones folclóricas, esta no se encuentra registrada en el SENAPI o en SOBODAYCOM. 
En cuanto a la piratería parecería que fuese una actividad lícita en Bolivia; a pesar de las trasgresiones tipificadas en la Ley y sus implicaciones penales, el fenómeno de la piratería se desenvuelve dentro de parámetros de aceptación y validación social con distintos argumentos.

El Derecho de Autor no conspira contra el desarrollo cultural de un pueblo, por el contrario fomenta la producción intelectual, porque al pagar al autor o compositor por sus derechos de reproducción o ejecución publica, se le está reconociendo por la obra de su creación, que en justicia le corresponde, dicho de otra manera se le incentiva a la creación y la generación de nuevas obras en el campo artístico musical, lo contrario supone un estancamiento y escasa motivación a la creación, de tal manera se podría llegar a la conclusión de que los países que protegen la propiedad intelectual de sus autores y compositores con seguridad deberían tener mayor producción, lo cual no sucede en Bolivia.

\section{CONCLUSIONES}

Partiendo del objetivo central de la investigación se puede concluir que existen muy pocos trabajos en Bolivia sobre el derecho de autor, y más aún cuando se trata del folclore nacional; El desconocimiento por parte de la mayoría de los abogados del Derecho de Autor, es un claro ejemplo de la poca importancia que se le da dentro del país a esta área, repercutiendo por su puesto en la creación de situaciones desventajosas para la negociación de acuerdos, tratados y convenios, además de escasas políticas de fomento e incentivación a autores y compositores de música folclórica boliviana, esto debido a la fácil vulnerabilidad de la normativa actual, la falta de coercibilidad y aplicación de la misma.

Cabe resaltar, que no existe una adecuada protección de los derechos de autores y compositores de música folclórica boliviana, por lo cual los mismos pierden cualquier estímulo y motivación para continuar su actividad creadora al no percibir la remuneración económica, traducida en bienestar material, que se deriva de la utilización de las obras, ocasionando la falta de identidad cultural en el ámbito folclórico musical de Bolivia.

\section{REFERENCIAS}

Código Penal. Ley $\mathrm{N}^{\circ} 1768$, del 10 de marzo de 1997

Constitución Política del Estado plurinacional de Bolivia Aprobada el 25 de Enero del 2009 Promulgada el 7 de Febrero del 2009

Consejo Nacional de la Cultura y las Artes. (2013). Guía de propiedad intelectual y derecho de autor. Chile: cultura

Fernández, Y. (2011). Fundamento y evolución del derecho de autor. España: Avilés

Gallardo, A. (2001). Acceso a la cultura y derechos de autor. Paraguay: LOM
Gómez, R. (2006). Lo que usted debe saber sobre Derecho. Bogotá: UNISABA

Jaramillo, A. (2010). Manual de Derecho de Autor. Colombia: CERLALC

Ley de Derecho de Autor. (13 de abril de 1992). Ley 1322. La paz, Bolivia: UPS

OMPI. (1979). Convenio de Berna. Convenio de Berna para la protección de obras literarias y artísticas. Paris 